\title{
Üniversite Kampüs Kantinlerindeki Gıdaların Mikrobiyolojik Kalitesinin ve Gıda Çalışanlarının E1 Hijyen Durumlarının Değerlendirilmesi ${ }^{\#}$
}

\author{
Şebnem PAMUK ${ }^{*}$, Metin ERDOĞAN², Yeliz YILDIRIM³ ${ }^{3}$, Harun HIZLISOY ${ }^{4}$, \\ Serhat AL ${ }^{5}$, Özgür SEPİN6
}

${ }^{1}$ Afyon Kocatepe Üniversitesi Veteriner Fakültesi, Besin Hijyeni ve Teknolojisi Anabilim Dal, Afyonkarahisar, TÜRKIYE

${ }^{2}$ Afyon Kocatepe Üniversitesi Veteriner Fakültesi, Veteriner Biyoloji ve Genetik. Anabilim Dal, Afyonkarabisar, TÜRKIYE

${ }^{3}$ Erciyes Üniversitesi, Veteriner Fakültesi, Besin Hijyeni ve Teknolojisi Anabilim Dal, Kayseri, TÜRKIYYE

${ }^{4}$ Erciyes Üniversitesi, Veteriner Fakültesi, Besin Hijjeni ve Teknolojisi Anabilim Dal, Kayseri, TÜRKIYYE

${ }^{5}$ Erciyes Üniversitesi, Veteriner Fakültesi, Besin Hijjeni ve Teknolojisi Anabilim Dal, Kayseri, TÜRKIYYE

${ }^{6}$ Sepin veteriner Kliniği, Ankara Yolu, Afyonkarabisar, TÜRKIYE

${ }^{\#}$ Calişma, AKÜ BAP Koordinasyon Birimi tarafindan 16VF 13 nolu proje ile desteklenmis ve 7. Veteriner Gida Hijyeni Kongresi’nde poster olarak sunulmustur.

*Corresponding author e-mail: spamuk@aku.edu.tr

\section{ÖZ}

Bu çalışmada, Afyon Kocatepe Üniversitesi Ahmet Necdet Sezer Kampüsü’nde gıda satışı yapan 6 adet kantinden yaz ve kış aylarında olmak üzere 2'şer kez örnekler alındı. Çalışma kapsamında çalışanların parmaklarından, dilimleme tahtalarından, bıçak saplarından ve değișik gıdalardan örnekler alınarak Aerob Mezofil Bakteri, S. aureus, Enterobactericeae, total koliform, Escherichia coli, sülfit indirgeyen anerob bakteriler, Listeria monocytogenes ve Salmonella spp., açısından analiz edildi. İncelenen 100 adet gida örneğinin \%91'inde toplam Aerob Mezofil Bakteri (AMB) $\geq 10^{3} \mathrm{kob} / \mathrm{g}, \% 21$ 'inde Enterobactericeae, \%64'ünde koliform bakteri, \%14'ünde E. coli, \%25'inde S.aureus $\geq 10^{2} \mathrm{kob} / \mathrm{g}$ düzeylerinde bulundu. Gıda örneklerinin (tavuk şiş) 1'inden Salmonella spp., \%3'ünden L. ivanovii, \%5'inden L. seeligeri, \%4'ünden L. welshimeri identifiye edilirken, sülfit indirgeyen anaerob bakteri ve L. monocytogenes saptanmadı. Biçak örneklerinin \% 77.5 'inde $\mathrm{AMB} \geq 10^{3} \mathrm{kob} / \mathrm{g}, \% 35$ 'inde Enterobactericeae, \%52.5'sinde koliform, \%12.5'inde E. coli, \%17.5'inde S.aureus, $\geq 10^{2} \mathrm{kob} / \mathrm{g}$ düzeylerinde identifiye edildi. Yüzey örneklerinin ise; $\% 55$ 'inde AMB $\geq 10^{3} \mathrm{kob} / \mathrm{g}, \% 29.6$ 'sında Enterobactericeae, \%37'sinde koliform bakteri, \%11'inde E. coli, \%14.8'inde S.aureus $\geq 10^{2} \mathrm{kob} / \mathrm{g}$ düzeylerinde tespit edildi. Gıda çalışanlarının el örneklerinin mikroorganizma kontaminasyon düzeyleri sırasiyla; örneklerin $\% 6.6$ 'sinda Enterobactericeae $\geq 2.5 \mathrm{kob} / \mathrm{cm}^{2}, \% 8.8$ 'inde $\geq 1.0 \mathrm{kob} / \mathrm{cm}^{2} ; \% 4.4$ 'ünde koliform bakteri $\geq 2.5$ $\mathrm{kob} / \mathrm{cm}^{2}$ ve $\% 15.5$ 'inde $\geq 1.0 \mathrm{kob} / \mathrm{cm}^{2} ; \% 14$. $\%$ 'sinde E. coli $\geq 1.0 \mathrm{kob} / \mathrm{cm}^{2} ; \% 15.5$ 'inde $S$. aureus $\geq 2.5 \mathrm{kob} / \mathrm{cm}^{2}$ ve $\% 15.5$ inde $\geq 1.0$ $\mathrm{kob} / \mathrm{cm}^{2}$ olarak belirlendi. El örneklerinden saptanan bu değerlerin literatürde belirlenen hedef değerlerin $\left(<2.5 \mathrm{kob} / \mathrm{cm}^{2}\right)$ üzerinde olduğu belirlendi.

Anahtar Kelimeler: Üniversite kampüsü, Gıda çalışanı, Gıda güvenliği bilgisi, İndikatör mikroorganizma, Kantinler

Evaluation of Hand Hygiene Situation of Food Handlers and Microbiological Quality of Retailed Some Foods in University Campus Canteen

\begin{abstract}
In this study, samples sailed six canteens were taken 2 times including the summer and winter in the Afyon Kocatepe University Ahmet Necdet Sezer Campus. Scope of work the fingers of workers, slicing boards, from the knife handle and various food samples were analyzed for mesophilic aerobic bacteria, S. aureus, Enterobactericeae, total coliform, E. coli, sulphite-reducing anaerobe bacteria $L$. monocytogenes and Salmonella. Contamination levels of 100 food samples were detected respectively; $91 \%$ of samples $\geq 10^{3} \mathrm{cfu} / \mathrm{g}$ TMAB, $\% 21$ Enterobactericeae $\geq 10^{2} \mathrm{cfu} / \mathrm{g}, 64 \%$ coliforms $\geq 10^{2} \mathrm{cfu} / \mathrm{g}, 14 \%$ E. coli $\geq 10^{2} \mathrm{cfu} / \mathrm{g}$ and $25 \% \mathrm{~S}$. aureus $\geq 10^{2} \mathrm{cfu} / \mathrm{g}$. Salmonella spp. was detected only one samples (chicken skewer). While 3\% L. ivanovii, $5 \%$ L. seeligeri, $4 \%$ L. welshimeri were isolated from all of the food samples, sulphite-reducing anaerobe bacteria and L. monocytogenes was not detected. The levels of microorganisms were found from the knife samples respectively; TMAB $\geq 10^{3} \mathrm{cfu} / \mathrm{g}$ (77.5\%); Enterobactericeae $\geq 10^{2} \mathrm{cfu} / \mathrm{g}(35 \%)$; coliforms $\geq 10^{2} \mathrm{cfu} / \mathrm{g}(52.5 \%) ;$ E. coli $\geq 10^{2}$ $\mathrm{cfu} / \mathrm{g}(12.5 \%) ; S$. aureus $\geq 10^{2} \mathrm{cfu} / \mathrm{g}(17.5 \%)$. Surface samples were found contaminated with TMAB $\geq 10^{3} \mathrm{cfu} / \mathrm{g}(55 \%) ;$ Enterobactericeae $\geq 10^{2} \mathrm{cfu} / \mathrm{g}(9.6 \%)$; coliforms $\geq 10^{2} \mathrm{cfu} / \mathrm{g}(37 \%)$; E. coli $\geq 10^{2} \mathrm{cfu} / \mathrm{g}(11 \%) ;$ S. aureus $\geq 10^{2} \mathrm{cfu} / \mathrm{g}(14.8 \%)$. None of the samples were not detected sulphite-reducing anaerobe bacteria, L. monocytogenes and Salmonella. Contamination levels of hand samples were detected respectively; Enterobactericeae $\geq 2.5 \mathrm{kob} / \mathrm{cm}^{2}(6.6 \%)$ and $\geq 1.0 \mathrm{kob} / \mathrm{cm}^{2}(8.8 \%)$ of samples; coliforms $\geq 2.5 \mathrm{kob} / \mathrm{cm}^{2}(4.4 \%)$ and $\geq 1.0$ $\mathrm{kob} / \mathrm{cm}^{2}(15.5 \%)$; E. coli $\geq 1.0 \mathrm{kob} / \mathrm{cm}^{2}(14.7 \%)$; S. aureus $\geq 2.5 \mathrm{kob} / \mathrm{cm}^{2}$ and $\geq 1.0 \mathrm{kob} / \mathrm{cm}^{2}(15.5 \%)$. It was concluded that these values determined from the hand samples were concluded above the target values $\left(<2.5 \mathrm{cfu} / \mathrm{cm}^{2}\right)$ in the literature.
\end{abstract}

Keywords: University campus, Food handlers, Knowledge food safety, Indicator microorganism, Canteens 


\section{GİRIŞ}

Dünya Sağlık Örgütü'ne (DSÖ) göre, her yll 600 milyon insan kontamine gida tüketimi sonucu hastalanmaktadır. Bunların 420.000'inin öldüğü, ölenlerin 125.000 'inin ise 5 yaşın altındaki çocuklardan oluştuğu rapor edilmiştir (WHO, 2015) Gida güvenliği, sürdürülebilir gelişmişliğin önemli bir bileşenidir. Çünkü, globalleşen gıda üretim süreci, gida güvenliği üzerinde önemli bir etki oluşturmuştur. $\mathrm{Bu}$ işleyiş, geniş populasyonların gereksinimlerini araştırma ve karşılama amacıyla üretim, dağııım ve pazarlamaya odaklanmıştır. Ancak, global gida bilgisine rağmen, biyolojik, kimyasal, fiziksel tehlikelerin varlığı satışa sunum hatalarına yol açmaktadır (WHO, 2013).

Okul yaşına giren çocuklar ve ergenler için güvenli g1da sağlanması, hükümetler ve diğer ilgili taraflar için büyük bir endişe kaynağı olup, söz konusu grubun sağlık, büyüme ve gelişmesini iyileștirmekte aynı zamanda gelişmekte olan ülkelerde eğitimin devam etmesini teşvik etmektedir (Afoakwa, 2005; Oranusi ve ark., 2007; Santana ve ark., 2009). Bu nedenle, kontaminasyonların neden olduğu gida kaynaklı hastalıklar, catering sektöründe önem teşkil etmektedir. Bu tip gida kaynaklı hastalık ve salginlar, dünya genelinde gözlenen mortalite ve morbiditeye büyük katkı sağlamaktadır (McIntyre ve ark., 2013). Kore'de gida kaynaklı hastalık vaka bildirimlerinin \%47'sinin, Brezilya'da \%11.6'sinın okul catering servislerine ait olduğu bildirilmektedir. (Santana ve ark, 2009; Ryu ve ark., 2011). Güney Wales'te 2005 yilinda okul yemeğinden E. coli O157:H7 vakas1 (Meldrum ve ark., 2009), Fransa'da 2010 yllında 544 yetişkinin etkilendiği Salmonella spp., kaynaklı gida zehirlenmesi, 2012 yllinda Almanya'da yüzden fazla okulda 11.200 öğrencinin etkilendiği norovirus salginı (Marzono ve Balzaretti, 2013), Gana'nın Accra Rejiyonal bölgesi'ndeki bir okulda 2007 yllında 1348 okul çocuğunu etkileyen gida zehirlenme vakas1 (WHO, 2009; WHO, 2012) bildirilmiştir. Malm ve ark., (2015) söz konusu durumların, gıdaların muhafaza koşullarındaki yetersizlikten ve aynı zamanda okullarda zehirlenme vakalarının tekrar oluşmasından kaçınmak için oluşturulmuş bir protokolun olmamasından kaynaklandığını bildirmiştir.

Gıda çalışanlarının tüm gıda kaynaklı salgınların \%97'sinden sorumlu olduğu tahmin edilmektedir (Egan ve ark., 2007). Bu nedenle, gıda çalışanlarının güvenli ve hijyenik gıda sağlamaya ilişkin sorumlulukları kritik öneme sahiptir (Greig ve ark., 2007). Gastro-intestinal hastalığa yakalanan gida çalışanlarının elleri vasıtasıyla zararlı mikroorganizmalar yayılmakta ve çapraz kontaminasyonlara yol açmaktadır (Abdul-Mutalib ve ark., 2012). Avrupa Birliği'nde, Avrupa Gida Güvenliği Otoritesi (EFSA, 2010) tarafindan 2008 yilında, toplam 5332 gida zehirlenmesi vakasından 45.622 kişinin etkilediği, 6230 kişinin hastanede tedavi altına alındığı, 32 kişinin ise öldüğü bildirilmiştir. Bu rapora göre; gıda hazırlanması esnasında personel kaynaklı bulaşmalar, uygun olmayan gida muhafaza yöntemleri, kontamine işlenmemiş katk1 maddesi kullanımı, uygun olmayan 1s1-zaman parametreleri ve yetersiz 1S1 işleminin başlıca sebepler olduğu rapor edilmiştir. Avrupa Birliği 852/ 2004 no'lu regülasyonuna göre, gıda hijyeni konusunda gıda çalışanlarının eğitilmeleri yasal bir gereklilik olup, gida ile teması olan personelin kendi iş alanlarına göre gida hijyeni konusunda eğitilmeleri ve denetlenmeleri teminat altına alınmıştır. Yapılan düzenlemelere rağmen, son zamanlarda İngiltere, İrlanda, Portekiz, Slovenya ve Türkiye'de yapılan çalışmalar gıda çalışanlarının hijyen bilgi ve uygulamalarının iyileştirilmesi gerektiğini ortaya koymaktadır (Baş ve ark., 2006; Bolton ve ark., 2008; Gomes-Neves ve ark., 2007; Jevsnik ve ark., 2008; Tokuç ve ark, 2009; Walker ve ark., 2003). Gıda çalışanları yoluyla meydana gelen gıda zehirlenmelerinde üç temel faktör rol almaktadır: 1) çalışanların konuya ilişsin bilgisi 2) tutumu ve 3) davranışları dır (Sharif ve AlMalki, 2010). Hizmet içi eğitim programları, çalışanların bilgisini artırmak için önemli olmakla birlikte, çok fazla bilgi vermek her zaman çalışanların tutum ve davranışlarında pozitif yönde bir değişikliğe neden olmayabilmektedir (AnsariLari ve ark, 2010). Bu nedenle birçok ülkede gida çalışanların bilgi, genel durum ve gida hazırlama uygulamalarıyla ilgili birçok çalışma yapılmıştır (Ansari-Lari ve ark, 2010; Bas ve ark, 2006; Capunzo ve ark, 2005; Jevsnik ve ark, 2008; Martins ve ark., 2012; Seaman ve Eves, 2010). Tüm bu çalşsmalarda, öncelikle hizmet içi eğitim gereklilikleri belirlenmiş, eğitim sonrası verilen eğitimin etkinliği değerlendirilmiş ve iyi kalitede gida üretiminin sürekliliğini sağlamak için söz konusu eğitimlerin süreklilik arz etmesi gerektiği vurgulanmıştır.

Kantin ortamlarında öğrencilerin tüketimine sunulacak gidaların hazırlanmasında görevli gida çalışanlarının iyi kaliteli gıda hazırlayabilmeleri için ilgili mevzuata uygun çalışma prensiplerini benimsemiş olmaları gerekmektedir. İlgili mevzuatlara rağmen, gida hazırlama esnasinda alınan güvenlik önlemlerinin yeterli olmadığı, çoğu yerde gıda hazırlamanın belli aşamalarında spesifik sanitasyon gerekliliklerinin göz ard1 edildiği, uygulanmadığı gözlemlenmektedir. Gıda güvenliği kapsamında iyi personel hijyeni ve sanitasyon uygulamaları, gida kaynaklı hastalıkların önlenmesinde temel basamak olarak görülmektedir. Çoğu gıda personelinin konuya ilişkin yeterli bilgi 
ve beceriye sahip olmasına karşın, halen birçok gida zehirlenme vakalarından g1da personelinden kaynaklanan kontaminasyonlar sorumlu tutulmaktadır (Ehiri ve Morris, 1996; Greig ve ark, 2007; Howes ve ark, 1996).

Patojenlerin muhtemel varlığına işaret eden mikroorganizmaları veya mikroorganizma grubunu tanımlayan mikrobiyel indikatörlerin varlı̆̆ı ve sayısı genel olarak sanitasyon programlarının etkinliğinin değerlendirilmesi için kullanılmaktadır (Moore ve Griffith, 2002). Hijyen uygulamaları ile ilişkili olarak, indikatör mikroorganizmalar, total canl bakteri say1s1, koliformlar, E.coli, Enterobactericeae ve S. aureus olarak tanımlanmıştır (Department of Health, South Africa, 2001). En yaygin gida kaynaklı hastalık, stafilokokal gida zehirlenmesi olmakla birlikte, diğer enfeksiyon etkenleri arasında E. coli, Salmonella, Listeria, Campylobacter, Bacillus ve Clostridium türleri yer almakta ve söz konusu etkenlerin sebep olduğu enfeksiyonlar ölümlere ve önemli ölçüde iş gücü kayıplarına yol açmaktadır (Talaro ve Talaro, 1996; Borch ve Arinder, 2002). İnsan kafa derisinde yaklaşı $10^{6} \mathrm{kob} / \mathrm{cm}^{2}$, koltuk altında $5 \times 10^{5} \mathrm{kob} / \mathrm{cm}^{2}$, karın bölgesinde $4 \times 10^{4}$ $\mathrm{kob} / \mathrm{cm}^{2}$, ön kol bölgesinde $1 \times 10^{4} \mathrm{kob} / \mathrm{cm}^{2}$, ellerinde $3.9 \times 10^{4}$ ile $4.6 \times 10^{6} \mathrm{kob} / \mathrm{cm}^{2}$ arasinda parmak ucunda ise 0 ile $300 \mathrm{kob} / \mathrm{cm}^{2}$ civarinda bakteri bulunduğu rapor edilmiştir (WHO, 2009). $\mathrm{Bu}$ bakteriler arasinda stafilokoklar ellerde bulunmalarına karşın, ana rezervuarı insan burun delikleridir. Bu mikroorganizma, subkutan ve deri enfeksiyonlar1, osteomyelit, pneumoni, apse, endokardit ve bakteriyemi gibi çok geniş bir enfeksiyon grubundan sorumludur (Gelatti ve ark., 2009). S. aureus giysi ve kuru yüzeyler gibi ortamları ve stresli çevre şartlarını tolere edebilen bir bakteridir (Chaibenjawong ve Foster, 2011). Bu sebeple ellerde ve yüzeylerde ilk kontaktan sonra uzun süreler canlı kalabilir (Kusumaningrum ve ark., 2002; Scott and BloomWield, 1990). E. coli bağırsak kökenli patojen bir mikroorganizma olup, genel olarak tuvalet hijyeni yetersizliğinden kaynaklanmakta ve yine gida ile temas halinde olan personelin eli ile gidaya bulaşmaktadır (Lues ve Tonder, 2007). Tüketime hazır gidaların, 1s1 uygulaması ya da pişirme sonrası dilimleme ve paketleme aşamalarında $S$. aureus ile kontamine oldukları, çevresel yüzeylerdeki $S$. aureus sayısında da artış belirlendiği, bu durumun çapraz kontaminasyonlar sonucu şekillendiği bildirilmiştir. Etken sıklıkla gıda çalışanlarının eldivenlerinde bulunmaktadir (Syne ve ark., 2013). Eldivenler, hazır gida satışı yapılan yerlerde çalışanlar tarafindan sıklıkla değiştirilmezse, çapraz kontaminasyonun en önemli kaynağını oluşturmaktadırr. Çünkü patojen bakteriler, eldiven yüzeyine yapışırlar. Eller doğru bir şekilde y1kanmadan eldivenlerin giyilmesi ile eldivenin içinin ve dışının kontamine edildiği, eldiven giyildiğinde, genellikle el y1kama işleminden kaçınıldığı belirtilmektedir. Bu durumda eldiven; llik, nemli bir ortam sağlamakta ve ellerdeki mikrobiyel gelişimi hızlandıran ve teşvik eden bir ortam oluşturmaktadır (Lues ve Van Tonder, 2007; Aycicek ve ark., 2004). Bu nedenledir ki, el hijyeni, patojen mikroorganizmaların geçişinin önlenmesinde, infeksiyon görülme sıklığının azalmasında oldukça önemli bir uygulamadır (Soares ve ark., 2012; Schweon ve ark., 2013). Su ve sabun ile y1kamayla, kontamine elden uzaklaştırılan bakteri oraninin (ortalama $\log _{10}$ azalma) 15 s'de 0.61.1; 30 s'de 1.8-2.8; 1 dk'da 2.7-3.0; 2 dk'da 3.3; 4 dk'da 3.7 düzeyinde azaldığ1 tespit edilmiştir (Rotter, 1999). Bu çalışmada Afyon Kocatepe Üniversitesi Ahmet Necdet Sezer Kampüsü'ndeki kantin ve kafeteryalarda farklı türde tüketime sunulan hazır gidalardan, dilimleme tahtalarından, bıçak saplarından alınan örnekler, AMB, total koliform, Enterobactericeae, E. coli, Staphylococcus aureus, sülfit indirgeyen anerob bakteriler, Listeria monocytogenes ve Salmonella spp. açisindan analiz edildi. Çalışan personelin elleri ise, koliform, Enterobactericeae, E. coli, Staphylococcus aureus bakımından incelendi. Ayrıca çalışma kapsamında, gıda satışı yapılan işletmelerde gıdaların mikrobiyel kalitesine etki edebilecek faktörleri (işletme, personel ve hijyen bilgileri) değerlendirmek amacıyla anket uygulaması yapıldı. Çalışma sonunda, anket sonuçları ile incelenen mikrobiyolojik parametreler arasında ilişki olup olmadığı değerlendirildi.

\section{MATERYAL ve METOT}

Çalışmada kampüs içerisindeki 6 farklı kantine ait örnekler, yaz ve kış dönemlerini kapsayacak şekilde incelendi. Yazın Haziran-Temmuz-Agustos, kışın Aralık-Ocak-Şubat aylarında, toplam 100 adet g1da örneği, 45 personelin el örneği, 27 adet kesim tahtas1 ve 40 adet biçak sap1 yüzey örneği topland1. El örnekleri Enterobactericeae, koliform, E. coli ve $S$. aureus yönünden; gıda, bıçak ve yüzey örnekleri ise; AMB, Enterobactericeae, total koliform, E. coli, S. aureus, sülfit-indirgeyen anaerob bakteri, $L$. monocytogenes ve Salmonella spp. bakimindan incelendi.

\section{Ellerin Örneklenmesi}

Satış yerlerinde çalışan personelin her iki eline ait, başparmak ve işaret parmağını örneklemek için selektif agar içeren RODAC petrileri kullanıldı. Bu amaçla işaret parmağı için S. aureus izolasyonunda Baird-Parker Agar'a (Oxoid CM 0275) alınan örnekler $24-48$ saat $37^{\circ} \mathrm{C}$ 'de inkube edildi. Etraf1 beyaz haleli siyah koloniler tipik $S$. aureus kolonileri olarak değerlendirilerek, koagulaz test (Oxoid, Staphytect test kit) ile doğrulandı. Çalışanlanın 
başparmaklarında Enterobactericeae, total koliform, E. coli türlerini tespit etmek amaciyla Chromocult coliform Agar (Merck, 1.10426) kullanıldı. Petriler $37^{\circ} \mathrm{C}$ 'de 24 saat inkube edildi. İnkubasyon sonucunda tipik somon-kırmız1 renk koloniler koliform grubu bakteri, koyu mavi-mor menekşe renginde olanlar E. coli ve renksiz koloniler ise Enterobactericeae familyasına ait olarak değerlendirildi (Blood ve Curtis 1995; De Boer 1998).

\section{Yüzeylerin Örneklenmesi}

Kesim tahtaları ve bıçak saplarını örneklemek için iç alanı $15 \mathrm{~cm}^{2}$ olan steril bir çerçevenin sınırladığ bölgeden 2 farklı swap örneği alınd1. Swap örneklerinden biri AMGC, total koliform E. coli, Enterobactericeae, S. aureus ve sülfit-indirgeyen anaerob bakterilerin sayımı için kullanıldı. Diğeri $L$. monocytogenes, Salmonella spp. izolasyonunun ilk adımı olan ön zenginleştirme aşaması için kullanıldı. $\mathrm{Bu}$ amaçla AMGC, total koliform E. coli, Enterobactericeae, S. aureus ve sülfit-indirgeyen anaerob bakterilerin sayımı için kullanılacak steril pamuklu swaplar (T56-A, Technical Service Consultants Ltd.) \%0.05 Sodyum tiyosülfat içeren maksimum geri kazanım sulandirma (MRD, maximum recovery diluent OXOID CM733) ajanı ile 1slatıldıktan sonra biçak ve kesim tahtaları yüzeylerine 3'er defa 3 yönde sürülerek örnekleme işlemi tamamlandi. Swaplar tekrar MRD tüplerine yerleştirildi (Redmond ve ark., 2004; Cordoba ve ark., 1999). Söz konusu tüpler soğuk zincir altında laboratuvara taşınarak steril peptonlu su ile seri dilusyonları hazırlanarak her bakteriye özel besi yerleri kullanılmak suretiyle ekimler yapıldı. Yüzey ve bıçak saplarından alınan swap örneklerini içeren tüpler, sayımı yapılacak olan diğer bakteriler için ilgili besi yerlerine ekim yapıldıktan sonra sülfit indirgeyen anaerob bakterilerin spor formlarının sayımı için $75^{\circ} \mathrm{C}^{\prime}$ de 20 dakika 1 s 1 işlemine tabi tutuldu. Isı işleminden sonra $1 \mathrm{ml}$ alınıp steril petrilere 1'er $\mathrm{ml}$ inokule edilerek üzerine $15 \mathrm{ml}$ Iron Sulfite Agar (Oxoid, CM 0079) dökülüp, soğutularak yaklaşık 5-10 ml aynı agardan ikinci kat döküm yapilarak anaerob koşullarda 24-48 saat $37 \pm 1{ }^{\circ} \mathrm{C}$ 'de inkube edildi. İnkubasyon sonunda siyah koloniler değerlendirmeye alındı (ISO, 2003). Kesim tahtaları ve bıçak saplarından alınan ikinci swaplar ise içerisinde $10 \mathrm{ml}$ half fraser broth bulunan steril tüplere alınarak direkt olarak ön zenginleştirme aşaması için kullanıldı. Swap örneklerinden L. monocytogenes izolasyonu için (ISO11290-1) prosedürü kullanıldı (ISO, 2004). Salmonella izolasyonu için ise, ISO 6579 (ISO, 2002) yöntemi uygulandi.

\section{Gıdaların Örneklenmesi}

İşletmelerden ayrıca steril poşetlere 100'er g gida örnekleri alınarak diğer örnekler ile birlikte soğuk zincir altında laboratuvara getirilerek 1-2 saat içerisinde analize alındı. Alınan gıda örneklerinden 10'ar g tartılarak, AMGC için Plate Count Agar (PCA)'a ekim yapilarak $30^{\circ} C^{\prime}$ de $48-72$ saat inkübe edildi. S. aureus için Baird Parker Agar'a ekim yapilarak $35^{\circ} \mathrm{C}$ 'de $24-48$ saat inkübasyonun ardindan tipik $S$. aureus kolonileri (etrafi beyaz hale ile çevrili siyah koloniler) sayılarak değerlendirmeye alındı (Baird ve Lee, 1995). Elde edilen koloniler koagulaz test kiti kullanılarak doğrulandı (Staphytect test kit OXOID). Total koliform E. coli ve Enterobactericeae familyasina ait bakteri türlerini tespit etmek amaciyla Chromocult Coliform Agar (Merck, 1.10426) kullanilarak, 35-370 C'de 24 saat inkubasyon sonucunda tipik somon-kırmız1 renk koloniler koliform grubu bakteri, koyu mavi-mor menekşe renginde olan koloniler E. coli ve renksiz koloniler ise Enterobactericeae familyasina ait olarak değerlendirildi (Blood and Curtis, 1995; De Boer, 1998). Sülfit-indirgeyen anaerob bakterilerin sayımı için Iron Sulfite Agar'a (Oxoid, CM 0079) ekim yapilarak, $37^{\circ} \mathrm{C}$ 'de 48 saat inkubasyonun ardindan siyah koloniler değerlendirmeye alındı (ISO, 2003).

L. monocytogenes izolasyonu ISO 11290-1 prosedürüne göre yapıld1 (ISO, 2004). Bu prosedüre gore; her bir örnekten $25 \mathrm{~g}$ alınarak steril stomacher poşetine konulduktan sonra üzerine 225 ml Half Fraser Broth (Oxoid, CM0895) eklenip homojenize edilerek $30^{\circ} \mathrm{C}$ 'de 24 saat inkube edildi. Daha sonra zenginleştirilme brothlarından $0.1 \mathrm{ml}$ alınarak içerisinde $10 \mathrm{ml}$ Fraser Broth bulunan tüplere aktarildıktan sonra 48 saat $37^{\circ} \mathrm{C}$ 'de selektif zenginleştirme aşaması gerçekleştirildi. Fraser brothlarda selektif zenginleştirme sıvısından bir öze dolusu alinıp Chromogenic Listeria Agar'a (Oxoid, CM1084) ve Listeria selektif agar'a (Oxford) (Oxoid, CM856) ekim yapıldı. Söz konusu selektif agarlar $37^{\circ} \mathrm{C}$ 'de 48 saat inkube edildi. Inkübasyon süresi sonunda Oxford agar'da etrafı siyah hale ile çevrili yeşilimsi röfle veren koloniler, chromogenic Listeria agar'da ise etrafi opak haleli yeşil-mavi koloniler şüpheli kabul edildi. Her bir besi yerinde 5 şüpheli koloni \%0.6'lik Yeast Extract Powder (TSYEA) (Oxoid LP0021) ilaveli Tryptic Soy Agar'a (Oxoid CM0131) geçilerek 24 saat $37^{\circ} \mathrm{C}$ 'de inkube edildi. Elde edilen izolatlar gram boyama hareketlilik testi, katalaz, oksidaz, hemoliz CAMP tesleri ve karbonhidrat kullanımı açısından test edilip aynı zamanda Listeria 12L Microbact sistemi (Oxoid MB1128A) ile biyokimyasal açidan identifiye edildi. Salmonella izolasyonu için ise, ISO 6579 (ISO, 2002) yöntemi uygulandi.

\section{Anket Uygulamas1}

Çalışmaya Afyon Kocatepe Üniversitesi Ahmet Necdet Sezer Kampüsü içinde yer alan 6 kantinde çalışan 45 kişi dahil edildi. Kantinlerde g1da güvenliği konusunda mikrobiyel kalite ile ilgili risk faktörlerine yönelik 27 sorudan oluşan bir anket uyguland. Anket uygulamaları mikrobiyolojik 
analizler için örnek toplama ile es, zamanlı olarak yapıldı. Araştırmada katılımcıların bilgi düzeyleri frekans ve yüzde dağılımları ile sunulmuş olup, değerlendirmelerde Ki-kare $\left(\chi^{2}\right)$ testi kullanıldı.

\section{BULGULAR}

İncelenen 100 adet g1da örneğinin \%91'inde toplam Aerob Mezofil Bakteri (AMB) $\geq 10^{3} \mathrm{kob} / \mathrm{g}$, $\% 21$ 'inde Enterobactericeae $\geq 10^{2} \mathrm{kob} / \mathrm{g}, \% 64$ 'ünde koliform bakteri $\geq 10^{2} \mathrm{kob} / \mathrm{g}, \% 14$ 'ünde E. coli $\geq 10^{2} \mathrm{kob} / \mathrm{g}, \quad \% 25$ inde S.aureus $\geq 10^{2} \mathrm{kob} / \mathrm{g}$ düzeylerinde bulundu. Gıda örneklerinin (tavuk şiş) 1'inden Salmonella spp., \%3'ünden $L$. ivanovii, $\% 5$ 'inden $L$. seeligeri, \%4'ünden $L$. welshimeri izole edilirken, L. monocytogenes ve sülfit indirgeyen anaerob bakteri saptanmadi.

Biçak örneklerinin \% $\%$ 7.5'inde $\mathrm{AMB} \geq 10^{3} \mathrm{kob} / \mathrm{g}$, \%35'inde Enterobactericeae $\geq 10^{2} \mathrm{kob} / \mathrm{g}, \% 52.5$ 'sinde koliform bakteri $\geq 10^{2} \mathrm{kob} / \mathrm{g}, \% 12.5$ 'inde E. coli $\geq 10^{2} \mathrm{kob} / \mathrm{g}, \quad \% 17.5$ inde S.aureus $\geq 10^{2} \mathrm{kob} / \mathrm{g}$ düzeylerinde identifiye edildi.

Yüzey örneklerinin ise; \%55'inde AMB $\geq 10^{3}$ $\mathrm{kob} / \mathrm{g}, \% 29.6$ 'sinda Enterobactericeae $\geq 10^{2} \mathrm{kob} / \mathrm{g}$, 37'sinde koliform bakteri $\geq 10^{2} \mathrm{kob} / \mathrm{g}, \% 11$ 'inde $E$. coli $\geq 10^{2} \mathrm{kob} / \mathrm{g}, \% 14.8$ inde S.aureus $\geq 10^{2} \mathrm{kob} / \mathrm{g}$ düzeylerinde tespit edildi. Bıçak ve yüzey örneklerinden sülfit-indirgeyen anaerob bakteri, $L$. monocytogenes ve Salmonella spp., izole edilmedi (Tablo 1).

El örneklerinin \%40'indan Enterobactericeae, \%51.1'inden koliform, \%57.7'sinden E. coli, $\% 57.7$ 'sinden S. aureus izole edildi. Örneklerin \%6.6'sinda Enterobactericeae düzeyi $>2.5 \mathrm{kob} / \mathrm{cm}^{2}$ ve $\% 8.8$ 'inde $>1.0 \mathrm{kob} / \mathrm{cm}^{2}$; koliform düzeyi $\% 4.4$ 'ünde $>2.5 \mathrm{kob} / \mathrm{cm}^{2}$ ve $\% 15.5$ 'inde $>1.0$ $\mathrm{kob} / \mathrm{cm}^{2}$; E. coli düzeyi $\% 14.7$ 'sinde $>1.0 \mathrm{kob} / \mathrm{cm}^{2}$; S. aureus düzeyi $\% 15.5$ 'inde $>2.5 \mathrm{kob} / \mathrm{cm}^{2}$ ve $\% 15.5$ 'inde $>1.0 \mathrm{kob} / \mathrm{cm}^{2}$ olarak belirlendi (Tablo 2).

Tablo 1: Gıda, bıçak ve yüzey örneklerinin mikrobiyolojik sonuçları

Table 1: Microbiological results of food, knife and surface samples

\begin{tabular}{|c|c|c|c|c|c|c|c|c|c|c|c|c|c|c|c|c|c|}
\hline \multirow{2}{*}{ Örnek } & \multirow{2}{*}{$\begin{array}{c}\text { Analiz } \\
\text { edilen } \\
\text { örnek } \\
\text { sayısı }\end{array}$} & \multicolumn{2}{|c|}{$\begin{array}{l}\mathrm{AMB} \\
\geq 10^{3}\end{array}$} & \multicolumn{2}{|c|}{$\begin{array}{l}\text { Enterobactericeae } \\
\qquad \geq 10^{2}\end{array}$} & \multicolumn{2}{|c|}{$\begin{array}{l}\text { Koliform } \\
\qquad \geq 10^{2}\end{array}$} & \multicolumn{2}{|c|}{$\begin{array}{l}\text { E. coli } \\
\geq 10^{2}\end{array}$} & \multicolumn{2}{|c|}{$\begin{array}{l}\text { S. aureus } \\
\quad \geq 10^{2}\end{array}$} & \multicolumn{2}{|c|}{$\begin{array}{c}\text { Sülfit } \\
\text { indirgeyen } \\
\text { anaerob }\end{array}$} & \multicolumn{2}{|c|}{$\begin{array}{c}\text { Salmonella } \\
\text { spp. }\end{array}$} & \multicolumn{2}{|c|}{ L. monocytogenes } \\
\hline & & $\mathrm{n}$ & $\begin{array}{c}\mathrm{b} \\
(\%)\end{array}$ & $\mathrm{n}$ & $\begin{array}{c}\mathrm{b} \\
(\%)\end{array}$ & $\mathrm{n}$ & $\begin{array}{c}\mathrm{b} \\
(\%)\end{array}$ & $\mathrm{n}$ & $\begin{array}{c}\mathrm{b} \\
(\%)\end{array}$ & $\mathrm{n}$ & $\begin{array}{c}\mathrm{b} \\
(\%)\end{array}$ & $\mathrm{n}$ & $\begin{array}{c}\mathrm{b} \\
(\%)\end{array}$ & $\mathrm{n}$ & $\begin{array}{c}\mathrm{b} \\
(\%)\end{array}$ & $\mathrm{n}$ & $\begin{array}{c}\mathrm{b} \\
(\%)\end{array}$ \\
\hline G1da & 100 & 95 & 91 & 56 & 21 & 62 & 64 & 64 & 14 & 56 & 25 & - & - & 1 & 1 & - & - \\
\hline Biçak & 40 & 38 & 77.5 & 14 & 35 & 21 & 52.5 & 5 & 12.5 & 7 & 17.5 & - & - & - & - & - & - \\
\hline Yüzey & 27 & 22 & 55 & 8 & 29.6 & 11 & 37 & 3 & 11 & 4 & 14.8 & - & - & - & - & - & - \\
\hline
\end{tabular}

n: pozitif örnek sayıs1

b: pozitif örnek yüzdesi

Tablo 2: Gıda çalışanlarının el hijyen profilleri

Table 2: Hand hygiene profiles of food handlers

\begin{tabular}{|c|c|c|}
\hline Mikroorganizma & Pozitif örnek sayıs1 (\%) & $\begin{array}{l}\text { Hedefi aşan } \\
\text { olumlu örnek sayısı }\end{array}$ \\
\hline Enterobacteriaceae ${ }^{*}$ & $18(40)$ & $\begin{array}{l}3(\% 6.6)) \geq 2.5 \mathrm{kob} / \mathrm{cm}^{2} \\
1(\% 8.8) \geq 1 \mathrm{kob} / \mathrm{cm}^{2}\end{array}$ \\
\hline Kolliform & $23(51.1)$ & $\begin{array}{l}2(\% 4.4) \geq 2.5 \mathrm{kob} / \mathrm{cm}^{2} \\
7(\% 15.5) \geq 1 \mathrm{kob} / \mathrm{cm}^{2}\end{array}$ \\
\hline E. coli & $29(57.7)$ & $8(14.7) \geq 1 \mathrm{kob} / \mathrm{cm}^{2}$ \\
\hline S. aureus* & $29(57.7)$ & $\begin{array}{l}7(\% 15.5)) \geq 2.5 \mathrm{kob} / \mathrm{cm}^{2} \\
7(\% 15.5)) \geq 1 \mathrm{kob} / \mathrm{cm}^{2}\end{array}$ \\
\hline
\end{tabular}

n: Farklı kantin ve kafeteryalardaki toplam el örneği sayısı

*: Hedef değer yok 


\section{TARTIŞMA}

Gıda kaynaklı hastalıkların büyük çoğunluğunun, gida hazırlama aşamasındaki yetersiz uygulamalardan kaynaklandığ $\quad$ bildirilmektedir (EFSA, 2010). Gıda çalışanları bu salgınlar ile uzun süredir ilişkilendirilmekte ve bu gidişatın azaldığına dair herhangi bir işaret bulunmamaktadır (Greig ve ark., 2007). Bu çalışmada, gıda çalışanlarının gıda güvenliğine ilişkin bilgi düzeylerinin doğru cevap skorunun (\%66.7 ile \%100 aras1) yüksek düzeye sahip olduğu gözlenmiştir. Fakat el örneklerinden elde edilen sonuçların bu durumla paralellik göstermediği saptanmıştır. Benzer şekilde Romanya'da küçük ve orta ölçekli işletmelerde gıda çalışanlarına yapılan anket sonuçlarındaki doğru cevap skoru \%63.2 olarak belirlenmiştir (Jianu ve Chiş, 2012). Genellikle eldiven kullanan gida çalışanlarının el yıkama alışkanlığına sahip olmadığı (Pittet ve ark., 2000) bildirilmiștir. Gıda sektöründe çalışan personelin bilinçsiz ve belki de alışkanlıkla vücut bölgelerine dokunduktan sonra gidaya temas etmeleri ve patojen bir bakteriyi gidaya bulaştırabileceklerinin farkında olmamaları (Green ve ark., 2007), uyumsuz olmakta 1srarc1 olmalar1, rol modelin bulunmayıș1, (Pittet ve ark., 2000) ne zaman ellerini yikayacaklarını bilmemeleri veya çoğunlukla yıkamamayı tercih etmeleri, kurumun el hijyenine önem vermemesi, el hijyeni etkisini bilmemesi, sabun ve dezenfektana ulaşamaması, kurumsal olarak düzenli şekilde el hijyen tanıtım, eğitim ve performans eksikliğinin geri bildiriminin olmaması gibi faktörlerin bu sonuca etkili olduğu düşünülmektedir. Green ve ark., (2007) yaptıkları çalışmada, çalışanların \%27'sinin el yıkama işlemini uygun olarak gerçekleştirdiklerini, \%32'sinin ise bu prosedüre uymadıklarını, en sık rastlanan durumun ise sabun kullanmadan el y1kama alışkanlığ1 olduğunu bildirilmiştir. Lues ve Van Tonder, (2007) yaptıkları çalısmada, personel el örneklerinin \%44'ünde Enterobactericeae'nın saptandığını, \%32'sinde koliform bakteri, bir personeldeki E. coli düzeyinin yasal limitleri aştığını, $S$. aureus düzeyinin ise $\% 88$ inde $<9.8 \times 10^{1} \mathrm{kob} / \mathrm{cm}^{2}$ olduğunu rapor etmişlerdir. Genel hijyen bilgisinin eğitim seviyesiyle direk ilişkili olduğu, en sık verilen yanlış cevapların mikrobiyel risklere ilişkin, çapraz kontaminasyon ve sicaklik kontrolleriyle ilgili sorulara ait olduğu bildirilmektedir (Jianu ve Chiş, 2012). Çalışanların yaptıkları işe yönelik tatmin duygularının gıda hijyen tutum ve davranışlarını önemli düzeyde etkilediği belirtilmektedir (Jevsnik ve ark., 2008; Ko, 2013). Ayrıca, kültürel ve sosyal gereksinimlerin, el hijyeni bilinciyle yakından alakalı olduğu, işe başlarken, her tuvalet çıkısıında, hapşırma veya öksürme sonrasinda, burun silme sonrasinda, kirli malzemeye dokunduktan sonra ellerin y1kanması ve dezenfekte edilmesi gerektiği üzerinde önemle durulmaktadır (Juuma, 2005).
Yapılan birçok çalışmada, gıda çalışanlarının bilgi, genel durum ve gida hazırlama uygulamaları incelemeye alınmıştır (Capunzo ve ark., 2005; Bas ve ark, 2006; Jevsnik ve ark., 2008; Santos ve ark., 2008; Ansari-Lari ve ark., 2010; Seaman ve Eves, 2010; Martins ve ark., 2012; Osaili ve ark., 2013). $\mathrm{Bu}$ çalışmaların tamamında, ilk olarak hizmet içi eğitim gereklilikleri belirlenmiş, verilen eğitimin etkinliği değerlendirilmiş ve iyi kalitede gida üretimini sağlamak için eğitimlerin süreklilik arzetmesi gerektiği vurgulanmıştır. Hijyen tutum ve alışkanlıklarındaki yanlış uygulamaların sadece hijyen eğitimiyle alakalı olmadığı, bu duruma pek çok faktörün etkili olabileceği üzerinde durulmaktadır. Bunlar arasında en önemlileri; düşük eğitimli personel (Çakıroğlu ve Uçar, 2008), iş değişimi (Burch ve Sawyer, 1991), mevsimsel işçilik (Travis, 1986), düşük maaş ve statü (Rennie, 1994) olarak belirlenmiştir.

El yıkama uygulamalarında, klorheksidin, glukonat içeren antibakteriyel sabun, el dezenfektanları, kağıt havlu kullanımı gibi doğru yaklaşımlarda, el kontaminasyon düzeyinin kayda değer bir şekilde (3 $\log$ kob ve daha fazla) azaldığı, bu şekilde çapraz kontaminasyon riskinin de miniminize edilebildiği kaydedilmiştir (Montville ve ark., 2010). Gıda ile temas halindeki yüzeylerin genel hijyenik durumlarının değerlendirilmesinde, koliformlar önemli yer tutmaktadır (Jackson ve ark., 2007). Bu çalışmada doğrama tahtalarının \%29.6'sinda Enterobactericeae, \%37'sinde koliform, \%11'inde E. coli, düzeyinin $\geq 10^{2} \mathrm{kob} / \mathrm{ml}$ olduğu saptanmış ve bu sonuçların temizlik standartlarındaki yetersizliğe işaret ettiği sonucuna varılmıştır. Aynı predominant mikrofloranın gıda çalışanlarının ellerinde ve bıçak saplarında da tespit edilmesi, potansiyel bir çapraz bulaşmanın varolduğunu düşündürmektedir. Bakteri, gida ile temasta olan yüzeye tutunmakta ve bu şekilde gıdaya çapraz bulaşma riski artmaktadır (Chen ve ark., 2001; Montville ve ark., 2010; Zhao ve ark., 1998). Çapraz kontaminasyon olgularının özellikle yeterince dekontamine edilmemiş kesim tahtalarından (\%58) ve biçaklardan (\%46) kaynaklandığı rapor edilmiştir (Redmond ve ark., 2004). En önemli aşamanın ise, ürünün dilimlenmesi sırasindaki uygulamalardan kaynaklandığ1 ortaya konmuştur (Uyttendaele ve ark., 1999; Little ve De louvois 1998). Bu sebeple gidalara el teması ve çapraz kontaminasyon özellikle tüketime hazır gıdalara (yıkamaya, 1şı işlemine veya herhangi başka bir işleme gerek duyulmadan yenilebilecek nitelikte olan gidalar) patojenlerin bulaşmasında potansiyel bir mekanizma olarak karşımıza çıkmaktadır (FDA/USDA, 2003). E. coli O157: H7, L. monocytogenes, Camphylobacter jejuni (C. jejuni), Clostridium perfringens (Cl. perfringens), Salmonella spp. 
ve S. aureus (Staphylococcus aureus) hayvansal g1dalardan sıklıkla izole edilen, farklı ülkelerde geniş populasyonları etkileyen hastalık vakalarına ve büyük ekonomik kayılara yol açan bakteriler olarak bilinmektedirler (Milard ve Rockliff 2003; Elson ve ark., 2004; Colombari ve ark., 2007; Newell ve ark., 2010). S. aureus, E. coli ve Salmonella türlerinin ellerde ve yüzeylerde uzun süreler (günlerce) canlı kalabildiği bildirilmiştir (Kusumaningrum ve ark., 2002). Bu çalışmada, g1da örneklerinin \%21'inde Enterobactericeae, \%64'ünde koliform, \%14'ünde E. coli, \%25'inde S. aureus kontaminasyon düzeyi $\geq 10^{2} \mathrm{kob} / \mathrm{g}$ olarak tespit edilmiştir. Sadece bir örnekten Salmonella spp., izole edilirken, L. monocytogenes saptanmamıştır. Benzer bir araştırmada, İngiltere ve Kuzey İrlanda, tüketime hazır kurutulmuş ve fermente et ürünlerinden oluşan toplam 2981 örneğin \%99'unun mikrobiyolojik kalite kriterleri bakımından kabul edilebilir limitlerde olduğu, örneklerin \%1.3'ünün $10^{2} \mathrm{kob} / \mathrm{g}$ 'dan fazla $S$. aureus içerdiği, hiçbirinin verotoksijenik $E$. coli içermediğ fakat sadece iki tanesinin Salmonella türleri ile kontamine olduğu ortaya konmuştur (Little, 1998). Bir başka çalışmada (Gillespie ve ark., 2000) da, tüketime hazır dilimlenmiş et ürünlerinin \%26'sının kabul edilebilir hijyenik niteliğe sahip olmadığ1, söz konusu örneklerde yüksek düzeyde E. coli, S.aureus, Listeria türleri ve/veya C. perfringens saptandiğ1 belirtilerek tatmin edici olmayan bu sonuçların genelde yüksek AMB yüküne bağlı olduğu vurgulanmıştır. Christison ve ark. 2008, 70 adet şarküteri ürününde AMB $9 \log \mathrm{kob} / \mathrm{g}$, koliform 5 $\log \mathrm{kob} / \mathrm{g}$, E. coli 6 log kob/g, S. aureus 2 log kob/g düzeylerinde tespit ettiklerini, örneklerin $\% 4$ 'ünün L. monocytogenes, \%16'sinin Salmonella spp., ile kontamine olduğunu rapor etmişlerdir. Yüzeylerden topladıkları örnekler arasında AMB bakımından en yüksek düzeyi kaşıklarda (5.1 log $\mathrm{kob} / \mathrm{g}$ ), doğrama tahtalarından ise koliform (4 log $\mathrm{kob} / \mathrm{g})$ ve E. coli (1.5 log $\mathrm{kob} / \mathrm{g})$ olarak saptadıklarını bildirmişlerdir.

\section{SONUÇ}

Gıda çalışanlarının ellerinde ve gida temas yüzeylerinde indikatör ve bazı patojen mikroorganizmaların varlığ1; iyi hijyen uygulamalarının noksanlığını, personel hijyen eksikliğini, işletme hijyen protokolündeki yetersizliği işaret etmektedir. Söz konusu patojen bakterilerden $S$. aureus genel olarak insanların burun mukozasinda ve el ve yüz yaralarında bulunmakta ve personel eli ile gidalara bulaşmaktadır. E. coli, genel olarak tuvalet hijyeni yetersizliğinden kaynaklanmakta ve yine gida ile temas halinde olan personelin eli ile gıdaya bulaşmaktadır. Analiz edilen diğer bakteriler çapraz kontaminasyonda ve personel hijyeninde önem arz eden Salmonella spp., ve L. monocytogenes'den oluşmaktadir. Sülfid indirgeyen mikroorganizmalar ise, muhtemel bir anaerob patojenin varlığına işaret etmesi bakımından değerlendirmeye alınmıştır. Bu çalışmadan elde edilen sonuçlar, yanlış uygulamaların düzeltilmesi konusunda çözüm önerileri sunulması ve bu vesileyle halk sağlı̆̆ının korunmasına yönelik önemli bir adım atılmış olması bakımından önem teşkil etmektedir. Ayrıca bu çalışma sonuçları, çalışanların ellerindeki ve gıda temas yüzeylerindeki kontaminantların son ürüne taşınmasının önlenmesi konusunda düzenlenecek eğitimlerin çerçevesini belirlemede fayda sağlayacaktır.

\section{KAYNAKLAR}

Abdul-Mutalib NA, Abdul-Rashid MF, Mustafa S, Amin-Nordin S, Hamat RA, Osman M. Knowledge, attitude and practises regarding food hygiene and sanitation of food handlers in Kuala Pilah, Malaysia. Food Control. 2012; 27: 289-293.

Afoakwa EO. Enhancing the quality of school feeding programme in Ghana. The Global Child Nutrition Forum 2005; Baltimore, Maryland, USA. (Available at:http://works.bepress.com/emmanuelohe neafoakwa/40).

Ansari-Lari M, Soodbakhsh S, Lakzadeh L. Knowledge, attitudes and practices of workers on food hygienic practices in meat processing plants in Fars, Iran. Food Control. 2010; 21: 260-263.

Aycicek H, Aydogan H, Küçükkaraaslan A, Baysallar M, Baoustaoflu AC. Assessment of the bacterial contamination on hands of hospital food handlers. Food Control. 2004; 15: 253-259.

Bas M, Ersun AS, Kıvanç G. The evaluation of food hygiene knowledge, attitudes, and practices of food handlers' in food businesses in Turkey. Food Control. 2006; 17(4): 317-322.

Blood RM, Curtis GDW. Media for 'total' enterobacteriaceae, coliforms and Escherichia coli. International Journal of Food Microbiology. 1995; 26(1): 93-115.

Bolton DJ, Meally A, Blair IS, McDowell DA, Cowan C. Food safety knowledge of head 
chefs and catering managers in Ireland, Food Control. 2008; 19(3): 291-300.

Borch E, Arinder P. Bacteriological safety issues in red meat and ready-to-eat meat products as well as control measures. Meat Science. 2002; 62: 381-390.

Burch NL, Sawyer CA. Food handling in convenience stores: the impact of personnel knowledge on facility sanitation. Journal of Environmental Health. 1991; 54(3): 23-27.

Çakıroglu FP, Uçar A. Employees' perception of hygiene in the catering industry in Ankara, Turkey. Food Control. 2008; 19(1): 9-15.

Capunzo M, Cavallo P, Boccia G, Brunetti L, Buonomo R, Mazza G. Food hygiene on merchant ships: the importance of food handlers' training. Food Control. 2005; 16: 183-188.

Chaibenjawong P, Foster SJ. Desiccation tolerance in Staphylococcus aureus, Archives of Microbiology. 2011; 193(2): 125-135.

Chen Y, Jackson, KM, Chea FP, Schaffer DW. Quantification and variability analysis of bacterial cross contamination rates in common food service tasks. Journal of Food Protection. 2001; 64(1): 72-80.

Christison CA, Lindsay D, von Holy A. Mictobiological survey of ready-to-eat foods and associated preparation surfaces in retail delicatessens, Johannesburg, South Africa. Food Control 2008; 19: 727-733.

Colombari V, Mayer M, Laicini ZM, Mamizuka E, Franco B, Destro MT, Landgraf M. Foodborne Outbreak Caused by Staphylococcus aureus: Phenotypic and Genotypic Characterization of Strains of Food and Human Sources. Journal of Food Protection. 2007; 70(2): 489-493.

Cordoba M, CordobA J, Jordano R. Microbiological hazards during processing of croquettes. Journal of Food Safety. 1999; 19 1-15.

Department of Health South Africa. Guidelines for environmental health officers on the interpretation of microbiological analysis data of food, Directorate. Food Control. 2001; Pretoria, Government Printer.
De Boer E. Update on media for isolation of enterobacteriaceae from foods. International Journal of Food Microbiology. 1998; 45(1): 43-53.

Egan MB, Raats MM, Grubb SM, Eves A, Lumbers ML, Dean MS, Adams MR. A review of food safety and food hygiene training studies in the commercial sector. Food Control. 2007; 18(10): 1180-1190.

Ehiri JE, Morris GP. Hygiene training and education of food handlers: does it work? Journal of Ecology of Food and Nutrition. 1996; 35: 243-251.

Elson R, Burgess F, Little CL, Mitchell R.T. Microbiological examination of ready-to-eat cold sliced meats and pâté from catering and retail premises in the UK. Journal of Applied Microbiology. 2004; 96: 499-509.

European Food Safety Authority (EFSA). The Community Summary Report on trends and sources of zoonoses, zoonotic agents and food-borne outbreaks in the European Union in 2008. The EFSA Journal. 2010; 1: 1410-1496.

FDA/USDA. Food and Drug Administration/United States Department of Agriculture. Quantitative assessment of relative risk to public health from foodborne Listeria monocytogenes among selected categories of ready to eat foods. 2003; available from http://www.foodsafety.gov/ dms/lmr2toc.html

Gelatti LC, Bonamigo RR, Becker AP, d'Azevedo PA. Staphylococcus aureus resistentes à meticilina: disseminação emergentena comunidade. Anais Brasileiros de Dermatologia. 2009; 84: 501-516.

Gillespie I, Little CL, Mitchell R. Microbiological examination of cold readyto-eat sliced meats from catering establishments in the United Kingdom. Journal of Applied Microbiology. 2000; 88: 467-474

Green LR, Radke V, Mason R, Bushnell L, Reimann DW, Mack JC. Factors related to food worker hand hygiene practice. Journal of Food Protection. 2007; 70: 661-666.

Greig JD, Todd EC, Bartleson CA, Michaels 
BS. Outbreaks where food workers have been implicated in spread of foodborne disease, Part 1. description of the problem, methods, and agents involved. Journal of Food Protection. 2007; 70: 1752-1761

Gomes-Neves E, Araújo AC, Ramos E, Cardoso CS. Food handling: comparative analysis of general knowledge and practice in three relevant groups in Portugal. Food Control. 2007; 18(6): 707-712.

Howes M, Mcewen S, Griffiths M, Harris L. Food handler certification by home study: measuring changes in knowledge and behavior. Dairy Food Environmental Sanitation. 1996; 16: 737-744.

International Organization for Standardization (ISO 6579). Microbiology of food and animal feeding stuffs-horizontal method for the detection of Salmonella spp. International Standard 2002; Geneva, Switzerland.

International Organization for Standardization (ISO 15213). International Organization for Standardization. 2003; Geneva, Switzerland.

International Organization for Standardization (ISO 11290-1/A1). International Organization for Standardization. 2004; Geneva, Switzerland.

Jackson V, Blair IS, McDowell DA, Kennedy J, Bolton DJ. The incidence of significant foodborne pathogens in domestic refrigerators. Food Control. 2007; 18: 346351.

Jevsnik M, Hlebec V, Raspor P. Food safety knowledge and practices among food handlers in Slovenia. Food Control. 2008; 19(12): 1107-1118.

Jianu C, Chiş C. Study on the hygiene knowledge of food handlers working in small and medium-sized companies in western Romania. Food Control. 2012; 26: 151-156.

Juuma PA. Hand hygiene: simple and complex. International Journal of Infectious Diseases. 2005; 9: 3-14.

Kusumaningrum HD, Van Putten MM, Rombouts FM, Beumer RR. Efects of antibacterial dishwashing liquid on foodborne pathogens and competitive microorganisms in kitchen sponges. Journal of Food Protection. 2002; 65: 61-65.

Ko WH. The relationship among food safety knowledge, attitudes and self-reported HACCP practices in restaurant employees. Food Control. 2013; 29(1): 192-197.

Little CL, De Louvois J. The microbiological examination of butchery products and butchers premises in the United Kingdom. Journal of Applied Microbiology. 1998; 85(1): 177-186

Little CL. The microbiological quality of readytoeat dried and fermented meat and meat products. International Journal of Environmental Health Research. 1998; 8(4): 277-284.

Lues JFR, Van Tonder I. The occurrence of indicator bacteria on hands and aprons of food handlers in the delicatessen sections of a retail Group. Food Control. 2007; 8: 326332.

Malm KL, Nyarko KM, Yawson AE, Gogo B, Lawson A, Afari E. Foodborne illness among school children in Ga East, Accra. Ghana Medical Journal. 2015; 49(2): 72-76.

Martins RB, Hogg T, Otero JG. Food handlers' knowledge on food hygiene: the case of a catering company in Portugal. Food Control. 2012; 23: 84-190.

Marzono MA, Balzaretti CM. Protecting child health by preventing school-related foodborne illnesses: microbiological risk assessment of hygiene practices, drinking water and ready-to-eat foods in Italian kindergartens and schools. Food Control. 2013; 34(2013): 560-567.

McIntyre L, Vallaster L, Wilcott L, Henderson SB, Kosatsky T. Evaluation of food safety knowledge, attitudes and self-reported hand washing practices in foodsafe trained and untrained food handlers in British Columbia, Canada. Food Control. 2013; 30(1): 150-156.

Meldrum RJ, Mannion PT, Garside J. Microbiological quality of ready-to-eat food served in schools in Wales, United Kingdom. Journal of Food Protection. 2009; 72(1): 197-201. 
Millard G, Rockliff S. Microbiological quality of sushi. 2003; available from: http://www.health.act.gov.au/c/health?a da\&did 10060511\&pid 1094601516.

Montville R, Chen Y, Schaffner D. Gloves barriers to bacterial cross-contamination between hands to food. Journal of Food Protection. 2010; 64: 845-849.

Moore G, Griffith CA. Comparison of surface sampling methods for detecting coliforms on food contact surfaces. Food Microbiology. 2002; 19: 65-73.

Newell DG, Koopmans M, Verhoef L, Aidara A. Sprong KH, Opsteegh M, Merel L, Threfall J, Scheutz F, vander Giessen J, Kruse H. Food-borne diseases-The challenges of 20 years ago still persist while new ones continue to emerge, Author links open overlay panel. International Journal of Food Microbiology. 2010; 139 (30): 3-15.

Oranusi S, Umoh VJ, Kwaja JKP. Energy intake and anthropometry: a case study of families in Zariai Nigeria. AJB. 2007; 6(4): 459-464.

Osaili TM, Abu Jamous DO, Obeidat BA, Bawadi HA, Tayyem RF, Subih Hadil S. Food safety knowledge among food workers in restaurants in Jordan. Food Control. 2013; 31: 145-150.

Pittet D, Hugonnet S, Harbarth S, Morouga P, Sauvan V, Touveneau S. (2000). Effectiveness of a hospital-wide programme to improve compliance with hand hygiene. Lancet. 356:1307-12.

Rennie DM. Evaluation of food hygiene education. British of Food Journal. 1994; 96(11): 20-25.

Redmond EC, Griffith CJ, Slader J, Humphrey TJ. Microbiological and observational analysis of cross contamination risks during domestic food preparation. British of Food Journal. 2004; 106(8): 581-597.

Rotter M. Hand washing and hand disinfection In: Mayhall CG (ed). Hospital epidemiology and infection control. Philadelphia, 1999; PA: Lippincott Williams \& Wilkins.

Ryu J, Ko J, Park H, Yang S, Kim H. Microbiological examination of nonheated foods served in feeding programmes of elementary schools, Iksan City, Jeonbuk Province, Korea. Journal of Food Protection. 2011; 47(9): 1564-1568.

Santana NG, Almeida RCC, Ferreira S J, Almeida FB. Microbiological quality and safety of meals served to children and adopted good manufacturing practices in public school catering in Brazil. Food Control. 2009; 20: 255-261.

Santos MJ, Nogueira JR, Patarata L, Mayan O. Knowledge levels of food handlers in Portuguese school canteens and their selfreported behaviour towards food safety. International Journal of Environmental Health Research. 2008; 18 (6): 387-401.

Schweon SJ, Edmonds SL, Kirk J, Rowland DY, Acosta C. Effectiveness of a comprehensive hand hygiene program for reductionof infection rates in a long-term care facility. American Journal of Infection Control. 2013; 41: 39-44.

Scott E, BloomWeld SF. The survival and transfer of microbial-contamination via cloths, hands and utensils. Journal of Applied Bacteriology. 1990; 68: 271-278.

Seaman P, Eves A. Food hygiene training: introducing the food hygiene training model. Food Control. 2010; 21(4): 381-387.

Sharif L, Al-Malki T. Knowledge, attitude and practice of Taif University students on food poisoning. Food Control. 2010; 21: 55-60.

Soares LS, Rogeria CC, Almeida RCC, Cerqueira ES, Carvalho JS, Nunes IL. Knowledge, attitudes and practices in food safety and the presence of coagulase-positive staphylococci on hands of food handlers in the schools of Camaçari, Brazil. Food Control. 2012; 27: 206-213.

Syne SM, A Ramsubhag, Adesiyun AA. Microbiological hazard analysis of ready-toeat meats processed at a food plant in Trinidad, West Indies, Infection Ecology and Epidemiology. 2013; 3(1): 1-12.

Talaro K, Talaro A. Foundations in microbiology 2nd edition Mc-Graw Hill Publishers USA. 1996; pp. 840-841.

Tokuç B, Ekuklu G, Berberoglu U, Bilge E, Dedeler H. Knowledge, attitudes and self- 
reported practice of food service staff regarding food hygiene in Edirne, Turkey. Food Control. 2009; 20(6): 565-568.

Travis HR. Training for seasonal foodservice operation. Journal of Environmental Health. 1986; 48(5): 265-267.

Uyttendaele M, De Troy P, Debevere J. Incidence of Listeria monocytogenes in different types of meat products on the Belgian retail market. International Journal of Food Microbiology. 1999; 53: 75-80.

Walker E, Pritchard C, Forsythe S. Food handlers hygiene knowledge in small food businesses. Food Control. 2003; 14(5): 339343.

WHO (World Health Organisation). Guidelines on hand hygiene in health care. 2009; www.who.int.

www.who.int/gpsc/5may/tools/978924159 7906/en/

WHO (World Health Organisation). Manual for integrated foodborne disease surveillance in the WHO African Region Brazzaville. 2012; WHO Regional Office for Africa.

WHO (World Health Organisation). Strategic plan for food safety including foodborne zoonoses 2013-2022. 2013; available at: http://www.who.int/foodsafety/strategicplan/en/ Retrieved June 25, 2017.

WHO (World Health Organisation). WHO's first ever globalestimates of foodborne diseases find children under 5 account for almost one third of deaths. 2015, available at: http://www. who.int/mediacentre/news/releases/2015/f oodborne -disease-estimates/en/. Retrieved June 25, 2017.

Zhao P, Zhao T, Doyle MP, Rubino JR. Meng

J. Development of a model for evaluation of microbial cross-contamination in the kitchen. Journal of Food Protection. 1998; 61: 960-963. 